\title{
Ontogeny of eyeblink conditioning in the rat: Effects of US intensity and interstimulus interval on delay conditioning
}

\author{
JOHN H. FREEMAN, JR. \\ University of North Carolina, Chapel Hill, North Carolina \\ CLARK O. SPENCER \\ U.S. Environmental Protection Agency, Research Triangle Park, North Carolina \\ RONALD W. SKELTON \\ University of Victoria, Victoria, British Columbia, Canada \\ and \\ MARK E. STANTON \\ U.S. Environmental Protection Agency, Research Triangle Park, North Carolina \\ and University of North Carolina, Chapel Hill, North Carolina
}

\begin{abstract}
Eyeblink conditioning in rat pups (17 or 24 days of age) was examined in two experiments, as a function of US intensity (Experiment 1) and interstimulus interval (ISI] Experiment 2). In Experiment 1, pups received three sessions of delay conditioning with a tone CS ( $380 \mathrm{msec}, 2.8 \mathrm{kHz}$, $90 \mathrm{~dB}$ [SPL]) and either a 1- or a 3-mA periocular shock US. Rats trained on Day 24 showed conditioning that increased as a function of US intensity. Pups trained on Day 17 did not condition with either US intensity level. Experiment 2 examined the effects of conditioning with ISIs of $280,560,1,120$, or 1,960 msec. Pups trained on PND24 showed a decrement in acquisition with ISIs longer than $280 \mathrm{msec}$. Seventeen-day-old pups were not conditioned at any of the ISIs used. The results indicate that the age-related development of eyeblink conditioning (Stanton, Freeman, \& Skelton, 1992) is not altered under these parametric conditions.
\end{abstract}

The purpose of the present study was to further pursue our attempt to develop eyeblink conditioning in the infant rat as a model for studying the ontogeny of learning (Stanton, Freeman, \& Skelton, 1992). In eyeblink conditioning, the stimuli that are being associated and the responses that they elicit can be specified and controlled precisely; and the neurobiological basis of conditioning in the adult is known (Thompson, 1988b). In addition, it involves neural systems-the hippocampus and cerebellum-that exhibit substantial postnatal development (Altman, 1982; Altman \& Bayer, 1975). For these reasons, we believe that eyeblink conditioning may provide a unique and powerful means of examining the development of learning, its neurobiological bases, and the mechanisms by

Supported in part by Grant 0GP43806-89 from NSERC, Canada, to R.W.S. We thank Jessica George, Beth Gregg, and Lauren Mills for their assistance in various phases of this research; Baker Bailey and Allen Lee for engineering support; and Diane Miller and Jeffrey Willner for reviewing an early version of the manuscript. Correspondence should be addressed to M. E. Stanton, Health Effects Research Laboratory (MD74B), U.S. Environmental Protection Agency, Research Triangle Park, NC 27711

Disclaimer-This manuscript has been reviewed by the Health Effects Re search Laboratory, U.S. Environmental Protection Agency, and approved for publication. Mention of trade names or commercial products does not constitute endorsement or recommendation for use. which pre- and postnatal events influence neurobehavioral development. Indeed, eyeblink conditioning is as promising a model for the analysis of development as it is for aging (Powell, Buchanan, \& Hernandez, 1991; Thompson, 1988a).

In our previous study, weanling (24-day-old) rat pups acquired conditioned eyeblink responses (CRs) to a tone conditioned stimulus (CS) paired with a periorbital-shock unconditioned stimulus (US) at a normal (adult) rate (within about 100 trials), whereas preweanling (17- to 18-day-old) pups showed less conditioning, even with threefold overtraining ( 300 trials). This age-related difference in the rate of conditioning did not appear to be due to differences in responsiveness to the CS or US, since startle responses to the CS and unconditioned responses (URs) to the US were equivalent at both ages. In addition, CRs were associative (i.e., limited to paired as opposed to unpaired CS-US presentations), and, at both ages, rate of conditioning could be enhanced by milk deprivation.

It has been well documented that parametric variation is critical for establishing the conditions under which infant organisms learn (Amsel \& Stanton, 1980; Spear \& Campbell, 1979; Spear \& Rudy, 1991). In the present study, we examined the role of two factors that might contribute to age-related differences in conditioning: differential sensitivity to US intensity and differential respon- 
siveness to a short (280-msec) CS-US interval (interstimulus interval, or ISI). US intensity is a critical parameter determining the rate and degree of eyeblink conditioning in both humans (Spence \& Platt, 1966) and rabbits (Smith, 1968). The failure of preweanling rats to acquire CRs could reflect the use of too low a US intensity. Similarly, the ISI has also been shown to be a critical parameter in eyeblink conditioning, with both human and rabbit adults showing optimal conditioning at ISIs of $250-500 \mathrm{msec}$ and poorer conditioning at longer ISIs (Kimble, 1947; Schneiderman \& Gormezano, 1964; Smith, 1968). However, there is evidence that the optimal ISI for infants may not be the same: human neonates (10-30 days old) become conditioned more rapidly at an ISI of $1,500 \mathrm{msec}$ than at shorter ISIs (Little, Lipsitt, \& Rovee-Collier, 1984). Therefore, the failure of preweanling rat pups to become conditioned could have resulted from the use of an ISI that was too short to support conditioning at this stage of development.

Two experiments were conducted to determine whether age differences in the rate of eyeblink conditioning during the weanling period could reflect ontogenetic differences in sensitivity to the US or conditionability at a short ISI. In Experiment 1, we examined the effects of US intensity by presenting a tone CS paired or unpaired with a periorbital-shock US of either 1 or $3 \mathrm{~mA}$. The intensities were higher and lower than the 2-mA US used previously, and the ISI was $280 \mathrm{msec}$-as before (Stanton et al., 1992). In Experiment 2, we examined the effects of the ISI by presenting the tone CS paired or unpaired with the US at ISIs of $280,560,1,120$, or $1,960 \mathrm{msec}$ in the paired groups, and equivalently long tones in the unpaired groups. The US intensity was $2 \mathrm{~mA}$, as before (Stanton et al., 1992). In both experiments, the CS was $100 \mathrm{msec}$ longer than the ISI, so that in the paired condition it overlapped and coterminated with the US. In the unpaired condition, the US was $100 \mathrm{msec}$, and it was explicitly unpaired with the CS so that the two stimuli occurred in pseudorandom order never less than $10 \mathrm{sec}$ apart.

\section{EXPERIMENT 1}

Experiment 1 was designed to determine whether the age-related difference in acquisition of eyeblink conditioning previously reported (Stanton et al., 1992) would be affected by varying US intensity. One possible outcome of varying US intensity was that 17-day-old rats would acquire eyeblink conditioning if trained with a more intense US. The 2-mA US used in previous experiments may have been insufficient for conditioning, even though it produced URs as large as those of older animals that showed clear conditioning (Stanton et al., 1992).

Another purpose of this experiment was to obtain a basic characterization of the US intensity function for eyeblink conditioning in 24-day-old rats. Previous studies of eyeblink conditioning in adult humans and rabbits have shown that conditioning rate increases with a stronger US (Smith, 1968; Spence \& Platt, 1966). It was predicted that, as in the adult human and rabbit, the acquisition rate in 24- day-old rats would change as a function of the US intensity.

In Experiment 1, pups were trained on delay conditioning or in a randomly unpaired control condition on Postnatal Day 17 (PND17) or PND24. Each of these groups was trained with either a 1- or a 3-mA periocular shock US. These US intensity levels were chosen because they represent a significant change above and below the $2-\mathrm{mA}$ US used in several previous experiments (Stanton et al., 1992).

\section{Method}

Subjects. Twenty-six 17-day-old and twenty-five 24-day-old Long-Evans rats drawn from 13 litters served as the subjects. They were offspring of time-bred females obtained from Charles River (Raleigh, NC) on either the 2 nd or the the 14th day of gestation. The offspring were raised in the animal colony at the Neurotoxicology Division, U.S. Environmental Protection Agency, Research Triangle Park, NC. (This facility is certified by the American Association for Accreditation of Laboratory Animal Care.) All subjects were maintained on a 12:12-h light:dark photoperiod, with light onset at 7:00 a.m. (All experimental procedures took place between 8:00 a.m. and 10:00 p.m.) The pups were born and housed with their mothers on a bed of wood shavings in plastic cages measuring $48 \times 27 \times 20 \mathrm{~cm}$. All litters were culled to 4 males and $4 \mathrm{fe}-$ males by the 3rd day after birth (the day of birth was designated as PND0). The subjects remained undisturbed with their mothers, except during periodic cage cleaning and experimental manipulations. Littermates were assigned to each of the eight experimental groups (see below), with the restriction that no more than 1 female and 1 male from each litter be assigned to a given group ( $n=5-7 /$ group; no gender effects were observed).

Apparatus. The eyeblink conditioning apparatus has previously been described in detail (Skelton, 1988; Stanton et al., 1992). It consisted of a Plexiglas test chamber fitted with a commutator, which carried an electrode lead to a head stage designed for freely moving subjects. The electrode lead ran from the commutator to peripheral equipment and an IBM-PC-compatible computer. This lead permitted delivery of a 100 -msec eye shock US $(60 \mathrm{~Hz}$, constantcurrent square wave, $1.0 \mathrm{~mA}$ or $3.0 \mathrm{~mA}$ ), and recording of EMG activity from the eyelid. Eyelid EMG was recorded differentially, amplified 10,000 - to 20,000 -fold, frequency filtered to pass activity between 0.3 and $3.0 \mathrm{kHz}$, and integrated (with a 45 -msec time constant). Eyelid EMG was not recorded during the US period, because of a large stimulation artifact. An overhead speaker delivered the tone CS ( $380 \mathrm{msec}, 2.8 \mathrm{kHz}, 90 \mathrm{~dB}$ [SPL]), which was presented against background noise from exhaust ducts of approximately $65 \mathrm{~dB}$.

Surgery. On the day prior to training (typically in the afternoon), the pups were removed from their home cages and anesthetized by exposure to methoxyflurane (Metofane, Pitman-Moore, Mundelein, IL) vapor in a closed container for $5 \mathrm{~min}$. The pups were placed on a wire-mesh floor that was raised above paper towels soaked with approximately $3 \mathrm{ml}$ of Metofane. Deep anesthesia was maintained by testing the pups for loss of reflexes during surgery and reexposing them to Metofane as necessary via a nose cone. Upon the onset of anesthesia, the pups were implanted with head stages according to a procedure that is more fully described elsewhere (Skelton, 1988). Briefly, differential EMG electrodes were subcutaneously implanted in the upper eyelid muscles, and a ground electrode was placed subcutaneously at the back of the neck. Bipolar stimulating electrodes (for delivering the US) were implanted subdermally, immediately dorsal-caudal to the left eye. The electrode leads terminated in Amphenol pins that were secured to the skull with dental acrylic, according to a procedure developed for infant rats by Gilbert and Cain (1980). The head stage was connected to 
a commutator, allowing the animal to move freely during testing. Following surgery, the 16-day-old pups were returned to their home cages with their dams, and the 23-day-old pups were placed individually in mouse tubs and given food and water ad lib.

Design. Whenever possible, each pup in a litter was assigned to one of the eight experimental groups. The pups were trained on either PND17 or PND24 in one of two training conditions: standard delay conditioning (paired), or an unpaired control condition (unpaired). These four groups were factored with two US intensity levels, yielding a 2 (PND17 vs. PND24) $\times 2$ (paired vs. unpaired) $\times 2$ (US $1 \mathrm{~mA}$ vs. US $3 \mathrm{~mA}$ ) design.

Procedure. The pups received three training sessions, each consisting of 100 trials. These sessions were run in a single day, at approximately 5- to 6-h intervals. Before the first session, the pups were given $10 \mathrm{~min}$ of habituation to the test chamber. In the paired condition, the training sessions consisted of 10 blocks of 10 trials of delay conditioning. Of these, 9 trials involved pairings of an auditory CS and periocular-shock US, and 1 trial was a CS-alone test trial. The CS was $380 \mathrm{msec}$ in duration; it coterminated with the 100 -msec US, thus yielding an ISI of $280 \mathrm{msec}$. The US intensity was either 1 or $3 \mathrm{~mA}$, depending on the subjects' group assignment (see experimental design above). Trials were separated by a variable intertrial interval that averaged $30 \mathrm{sec}$ (range $=18-42 \mathrm{sec}$ ). In the unpaired control condition, the CS and US were presented in a pseudorandom order such that no more than three presentations of either stimulus occurred consecutively. The average interval between "trials" (stimuli) was $15 \mathrm{sec}$ (range $=9-21 \mathrm{sec}$ ), and each session contained $100 \mathrm{CS}$ and 100 US presentations. In this way, the paired and unpaired groups received the same number of stimulus presentations at the same average rate across each session. Eyelid responses were scored when the EMG signal exceeded 0.4 units above baseline. Startle responses (SRs) were defined as eyelid responses that occurred during the first $80 \mathrm{msec}$ of the $C S$ period. Responses that occurred during the remainder of the CS period were defined as CRs, and responses that occurred after the US period were defined as URs.

\section{Results and Discussion}

Figure 1 shows the results in terms of mean percentage CRs across 10-trial blocks of training (interrupted lines indicate session breaks). Of the eight experimental groups, only the animals given paired training on PND24 with a 3.0-mA US showed conditioning within 300 trials.

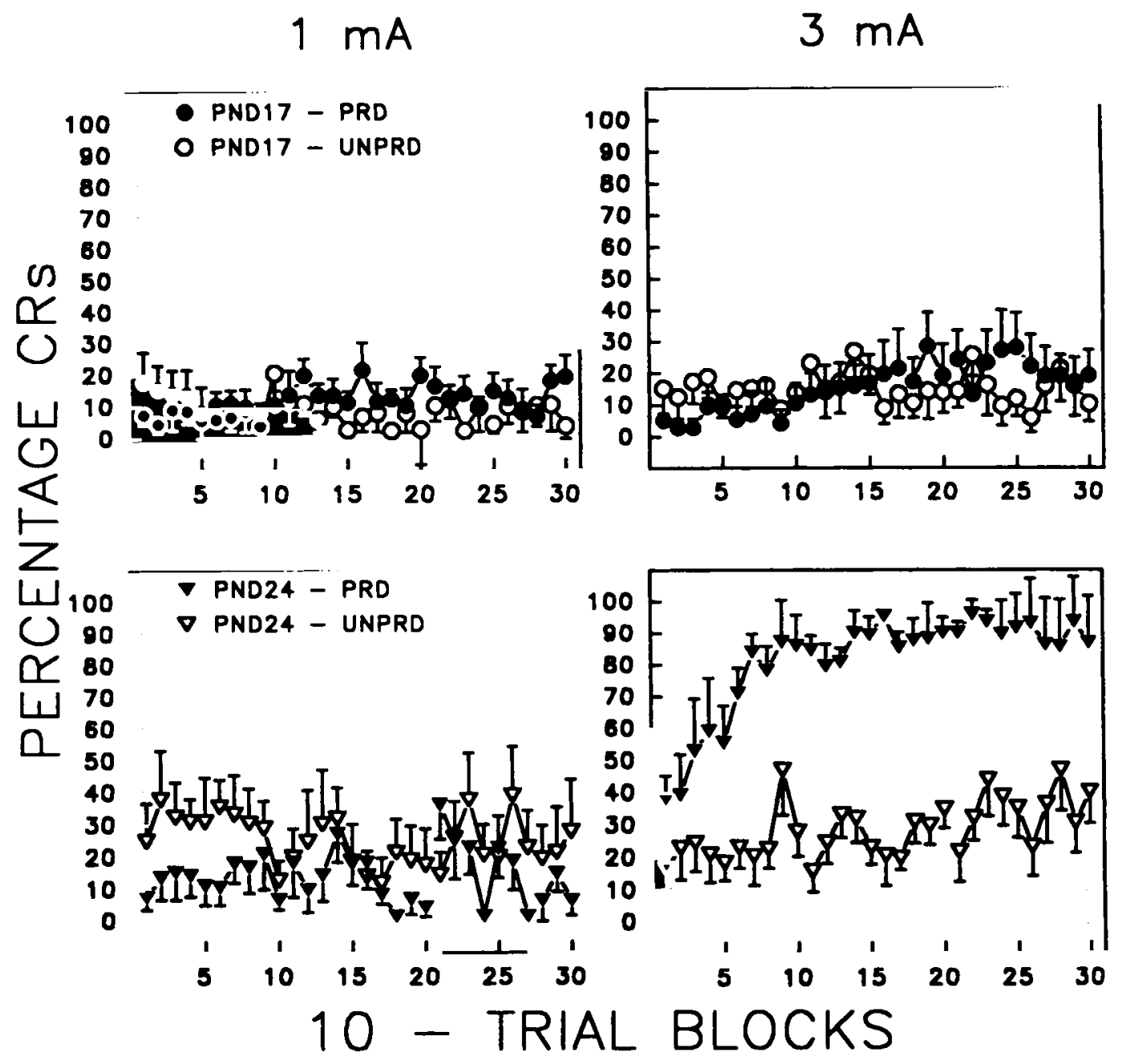

Figure 1. Mean ( $\pm S E$ ) percentage of conditioned responses (CRs) for 17- (circles) and 24-day-old (triangles) rats, as a function of training condition (filled symbols = paired; open symbols = unpaired), unconditioned stimulus intensity (left graphs = $1 \mathrm{~mA}$; right graphs $=3 \mathrm{~mA}$ ), sessions, and trial blocks (10 blocks of 10 trials per session). (Interruptions in the lines connecting data points represent session breaks. PND = postnatal day.) 
In contrast, the 17-day-old pups did not show conditioning at either US intensity. There was no increase in CRs in any of the unpaired groups. Therefore, the rate of eyeblink conditioning was influenced by US intensity on PND24 but not on PND17. These findings were supported by an analysis of variance (ANOVA), which revealed a significant interaction of age $\times$ condition $\times$ US intensity $[F(1,42)=19.92, p<.001]$. Post hoc tests (NewmanKeuls) of this interaction revealed that the animals trained on PND24 with the paired condition at $3 \mathrm{~mA}$ differed from all the other experimental groups (all comparisons, $p<.05$ ), and that these groups did not differ among themselves $(p>.05)$.

An additional analysis of peak CR amplitudes for each rat pup on each training session (Figure 2) showed that 24-day-old rats trained in the paired condition with a 3-mA US exhibited much higher amplitude CRs than did any other group and that only they showed a dramatic increase in responding across sessions. These results were confirmed by an ANOVA, which revealed a significant session $x$ age $\times$ condition $\times$ US intensity interaction $[F(2,84)=$ $10.51, p<.0001$ ]. Post hoc tests (Newman-Keuls) revealed that the 24-day-old rats trained in the paired condition with a 3-mA US exhibited higher CR amplitudes than did any other group (all comparisons, $p<.01$ ), and that their CR amplitudes increased across sessions $(p<$ $.01)$. The 24-day-old rats trained in the unpaired condition with a 3-mA US showed a slight increase in CR amplitude from Sessions 1 to 3 ( $p<.05$ ). However, this increase was trivial in comparison with that for the 24day-olds trained in the paired condition, and the two groups (paired and unpaired) differed significantly on all
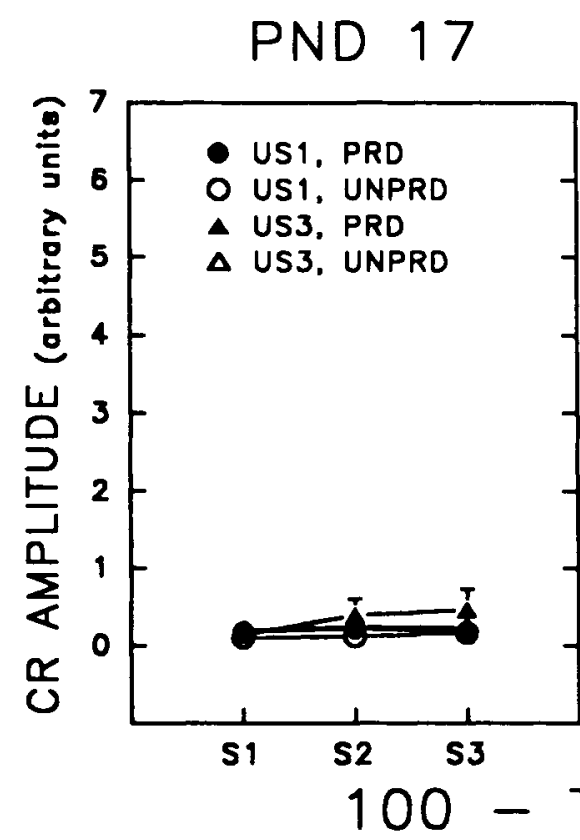

Figure 2. Mean ( $\pm S E$ ) conditioned response (CR) peak amplitudes for 17- (left) and 24-day-old (right) rats, as a function of training condition (filled symbols = paired; open symbols = unpaired), unconditioned stimulus (US) intensity (triangles = $1 \mathrm{~mA}$; diamonds = $3 \mathrm{~mA}$ ), and sessions (10 blocks of 10 trials per session). (PND = postnatal day.)

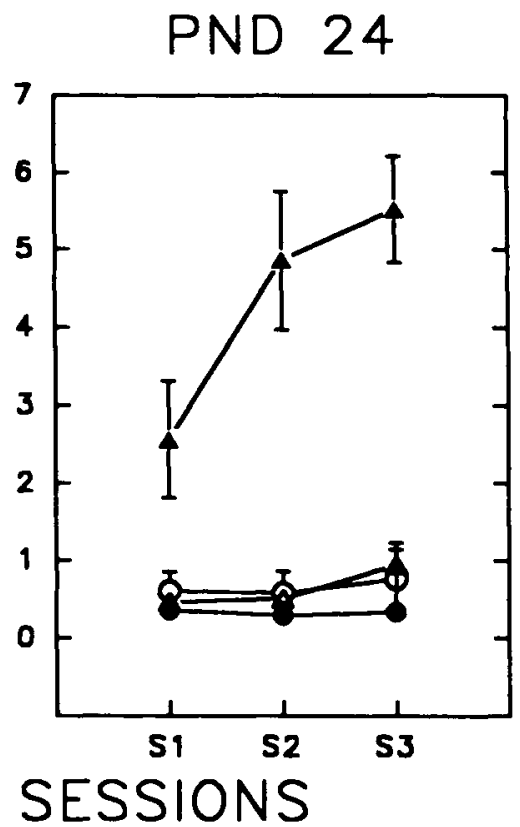

three sessions (all comparisons, $p<.01$ ). Thus, CR amplitude analysis demonstrated that 17 - and 24-day-old rats were differentially affected by increasing the US intensity from 1 to $3 \mathrm{~mA}$ and that this effect was related to associative processes.

In sum, only the 24-day-old rats trained in the paired condition showed responding that changed as a function of US intensity. The pups in this group did not show conditioning with a 1-mA US, but showed very rapid acquisition when a 3-mA US was used. Moreover, the asymptotic level of conditioning in 24-day-olds trained with a 3-mA US was approximately $90 \%$ CRs.

The performance of animals trained on PND17 was not affected by these variations in US intensity. This makes it unlikely that the failure to see conditioning in 17-dayold pups in previous reports reflected the use of a US of inadequate intensity. If the age-related change in eyeblink conditioning acquisition is related to the use of particular conditioning parameters, US intensity is probably not one of them.

\section{EXPERIMENT 2}

Experiment 2 was designed to determine whether the absence of conditioning in 17-day-olds reported previously (Stanton et al., 1992) reflected developmental changes in the optimal ISI. In our initial report, we used an ISI of $280 \mathrm{msec}$, which supports robust conditioning in adult rats and which corresponds well with the optimal ISI for NMR conditioning in the adult rabbit $(250 \mathrm{msec}$; Schneiderman \& Gormezano, 1964; Smith, 1968; Smith, Coleman, \& 
Gormezano, 1969). However, eyeblink conditioning studies in infant humans have suggested that parameters used to condition adults may not be appropriate for conditioning infants. Whereas the optimal ISI for eyeblink conditioning in adult humans is around $500 \mathrm{msec}$ (Kimble, 1947), human infants (as young as 10 days of age) condition more rapidly with a $1,500-\mathrm{msec}$ than with a 500-msec ISI (Little et al., 1984). Thus, the optimal ISI for infant rats may be longer than that for older rats. This led us to determine whether ISIs longer than $280 \mathrm{msec}$ would promote conditioning in 17-day-old rats. Another question of interest was whether longer ISIs would improve or impair conditioning in 24-day-old rats. If conditioning in 24-dayold rats is "adultlike," we would expect performance to decrease with longer ISIs.

\section{Method}

Subjects. Fifty-four 17-day-old and fifty 24-day-old Long-Evans rats drawn from 23 litters served as subjects. All other information regarding the subjects was identical to that given for Experiment 1.

Surgery and Apparatus. The apparatus and surgical procedures were identical to those used in Experiment 1.

Design. Each pup in a litter was assigned to one of 16 experimental groups. The pups were trained on either PND17 or PND24, in either paired or unpaired conditioning groups, with ISIs of 280,560 , 1,120 , or $1,960 \mathrm{msec}$. This yieided a 2 (PND17 vs. PND24) $\times$ 2 (paired vs. unpaired) $\times 4$ (ISI of 280 vs. 560 vs. 1,120 vs. $1,960 \mathrm{msec}$ ) factorial design.

Procedure. The training procedures for both the paired and the unpaired conditions were identical to those used in Experiment 1, except for the CS duration and US intensity. The US intensity was set at $2 \mathrm{~mA}$ for all animals tested. Tones used as the CS were identical in frequency and intensity to those used previously, but differed in duration $(380,660,1,220$, and $2,060 \mathrm{msec}$, respectively). To collect comparable data across differing trial durations, the EMG sampling rate was adjusted proportionally $(4,8,16$, or $28 \mathrm{msec} / \mathrm{sam}$ ple, respectively).

\section{Results and Discussion}

The results are presented in Figure 3 in terms of the mean percentage of CRs, as a function of 10-trial blocks. Animals trained at the $280-\mathrm{msec}$ ISI provided a replication of our previous findings (Stanton et al., 1992, Experiment 4). At this ISI, conditioning was seen only in the 24-day-old rats trained in the paired condition. There was no evidence of conditioning in any other group, at any age, condition, or ISI. No other paired group was significantly better than its unpaired control. These findings were supported by an ANOVA, which revealed a significant age $\times$ ISI $\times$ condition interaction $[F(3,88)=$ 4.43, $p<.01$ ]. Post hoc tests (Newman-Keuls) indicated that the 24-day-old animals trained in the paired condition with a $280-\mathrm{msec}$ ISI responded at higher levels than did all other experimental groups (all comparisons, $p<$ $.05)$, including its unpaired control group $(p<.01)$. The only other difference was that the 24-day-old animals trained in the paired condition with a 1,960 -msec ISI responded less than their unpaired counterparts $(p<.05)$.

An additional analysis examined peak CR amplitudes (Figure 4). At the 280-msec ISI, conditioning was seen only in the 24-day-old rats trained in the paired condi- tion. As in the percentage CR analysis, there was no evidence of conditioning in any other group or condition. at any age, or ISI. These findings were supported by an ANOVA, which revealed a significant age $\times$ ISI $\times$ condition interaction $[F(3,88)=7.91, p<.001]$. Post hoc tests (Newman-Keuls) indicated that the 24-day-old animals trained in the paired condition with a $280-\mathrm{msec}$ ISI showed higher amplitude responses than did all other experimental groups (all comparisons, $p<.01$ ), including its unpaired control group $(p<.01)$. The 24-day-old animals trained in the paired condition with either a 560 or 1,960-msec ISI responded less than their unpaired counterparts $(p<.05, p<.01$, respectively). Analysis of peak $C R$ amplitude thus confirmed the results of the percentage CR analysis, further demonstrating that only 24-day-old rats trained with the 280-msec ISI in the paired condition expressed the conditioned eyeblink response.

Both the CR percentage and the peak CR amplitude analyses showed an increase in CRs in the animals trained in the unpaired condition at longer ISIs. At 24 days, this percentage was higher than in paired animals. However, analysis of the amplitude of averaged responses did not confirm this effect. The amplitude of the averaged response was measured from the averaged EMG response of a given rat across an entire session. The averaged response, much like an averaged evoked potential, is a pointby-point average across the sampled duration. Thus, $\mathrm{CRs}$ that occur randomly during the CS period will not influence the averaged response as much as CRs that occur reliably within a more restricted part of the CS period. Thus, this method of analysis demonstrates the degree to which the peak of the CR is time-locked to either CS or US onset. The 24-day-old rats trained with a $280-\mathrm{msec}$ ISI in the paired condition showed higher amplitude CRs than did any other group, and they were the only ones to differ from their unpaired controls. In contrast to what was seen with the percentage-CR and CR-amplitude measures, unpaired animals trained at ISIs exceeding 280 msec did not respond at significantly higher levels than did paired animals when the amplitude-of-averagedresponse measure was used. These results were confirmed by an ANOVA for comparing the 17- and 24-day-old rats trained in both the paired and the unpaired conditions at each ISI. There was a significant age $\times$ condition $\times$ ISI interaction $[F(3,84)=7.27, p<.001]$. Newman-Keuls tests showed that the 24-day-old group trained in the paired condition with a 280 -msec ISI were significantly superior to all other groups (all comparisons, $\mathrm{p}<.01$ ), and that it was the only group to differ significantly from its unpaired control group $(p<.01)$.

The different results obtained with percentage-CR, peak-CR-amplitude, and amplitude-of-averaged-CR measures suggest that the "CRs" seen in the unpaired groups at longer ISIs were unlike those seen at the 280 -msec ISI. They were not time-locked to either CS or US onset and were much lower in amplitude. This was also apparent from visually scanning the EMG records. Figure 5 shows representative averaged responses on CS-alone test trials 
PND 17

ISI 280

PND 24
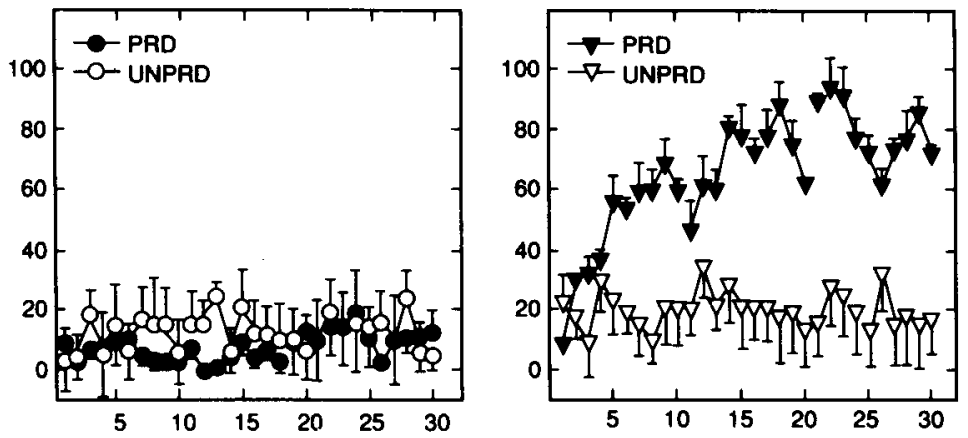

ISI 560
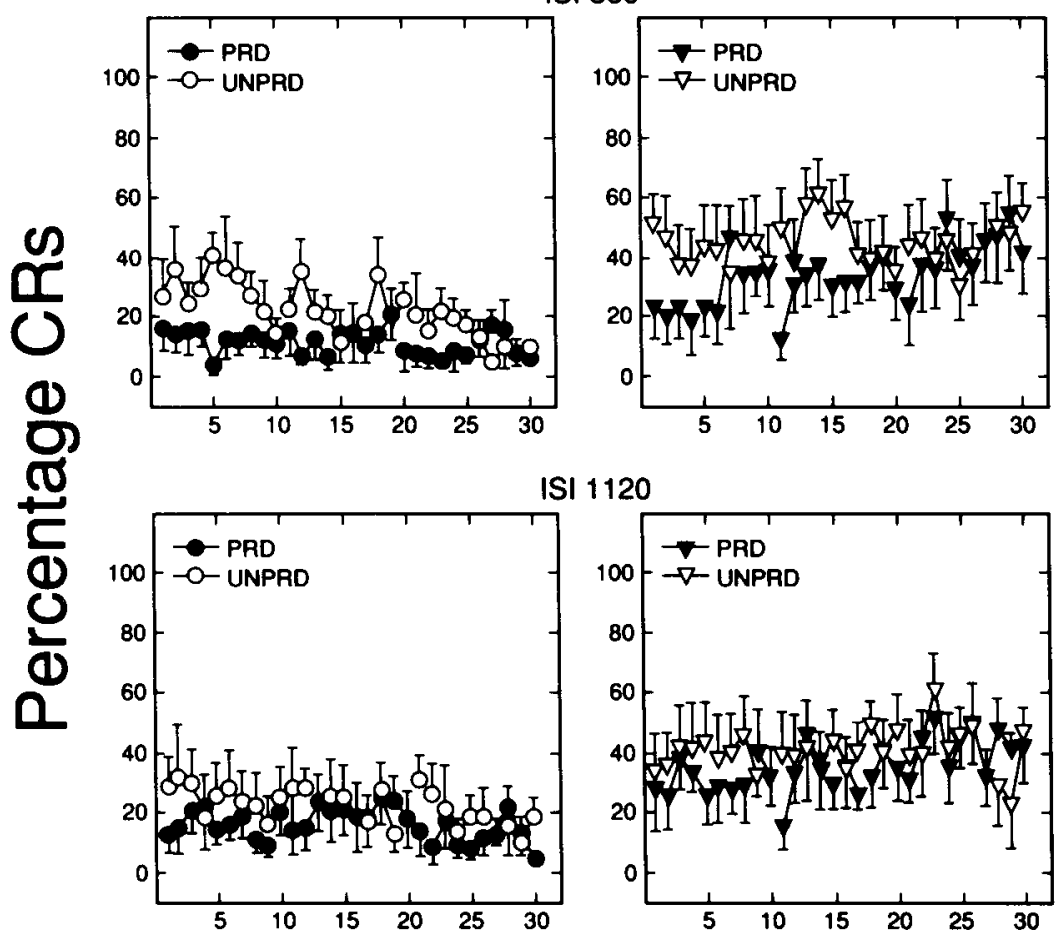

ISI 1120

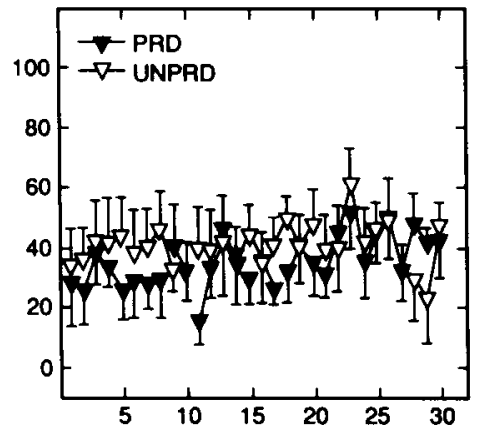

ISI 1960

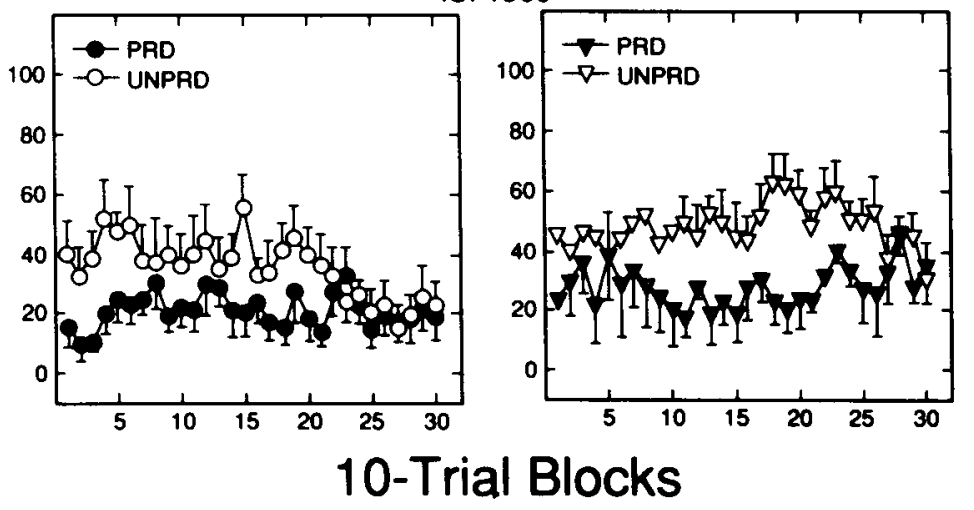

Figure 3. Mean ( $₫ S E$ ) percentage of conditioned responses (CRs) for 17- (left panels) and 24-day-old (right panels) rats, as a function of training condition (closed symbols = paired; open symbols = unpaired), sessions, and trial blocks (10 blocks of 10 trials per session), and interstimulus interval (ISI) in milliseconds. (Interruptions in the lines connecting data points represent session breaks. PND = postnatal day.) 


\section{ISI 280}

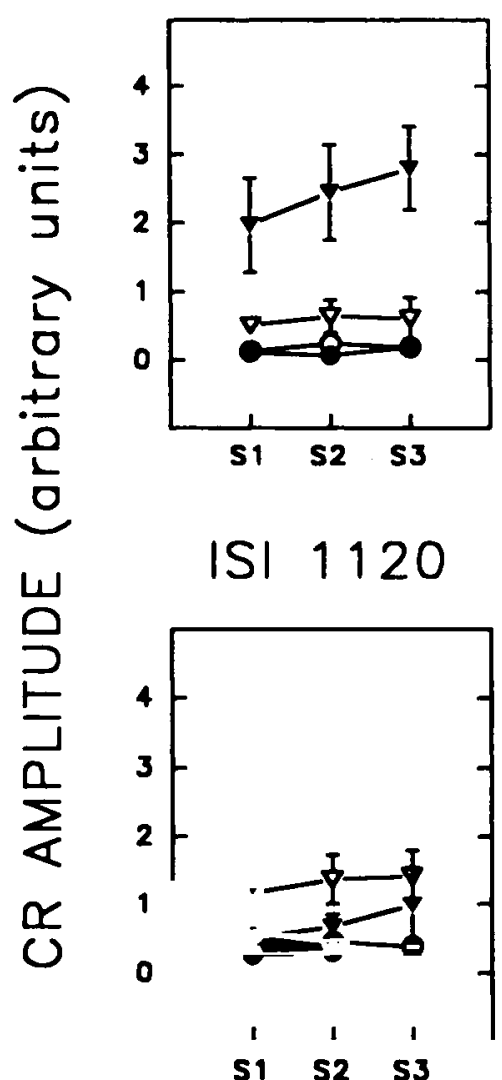

ISI 560
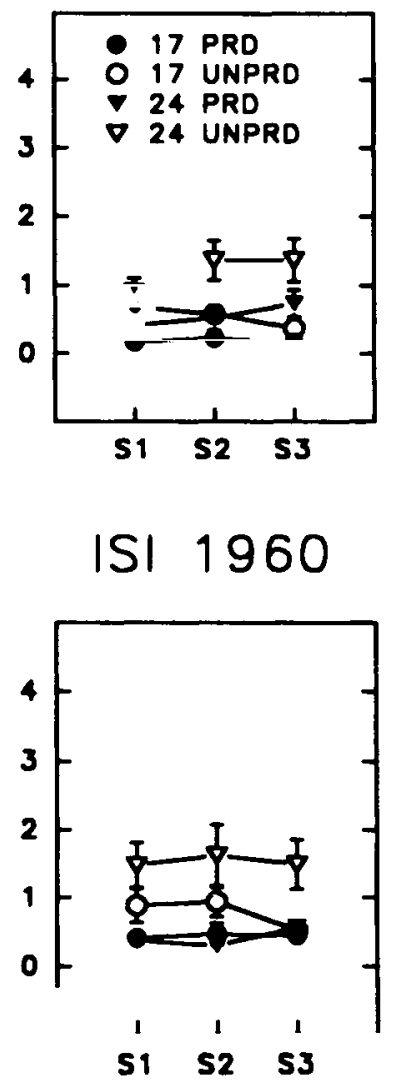

\section{0-BLOCK SESSIONS}

Figure 4. Mean ( $\pm S E$ ) conditioned response $(C R)$ peak amplitudes for 17- (circles) and 24-day-old (triangles) rats as a function of training condition (closed symbols = paired; open symbols = unpaired), and sessions ( 10 blocks of 10 trials per session), and interstimulus interval (ISI) in milliseconds. (PND = postnatal day.)

for the 17- and the 24-day-old pups trained in both the paired and the unpaired conditions, at either the 280 - or the 1,960-msec ISI. At the 1,960-msec ISI, responses recorded as CRs in the percentage-CR analysis were qualitatively different from those seen in animals trained with a 280-msec ISI. These responses were much lower in amplitude and improperly timed within the tone period, whereas at 280-msec, CRs were higher in amplitude and consistently timed. Because of these characteristics, we consider these responses to be of minor importance, perhaps reflecting a preferential sensitivity to pseudoconditioning, or, alternatively, an increase in motor activity that influenced the eyelid EMG record.

In sum, the findings of Experiment 2 indicate that increasing the training ISI does not improve conditioning in 17-day-old rats, and that previous failures to condition animals at this age were not due to the use of an inappropriately short ISI. The performance of 24-day-old rat pups was generally consistent with studies of eyeblink conditioning in adult rabbits (Schneiderman \& Gormezano,
1964; Smith, 1968; Smith et al., 1969), in that the rate of CRs decreased as the ISI increased (though perhaps more abruptly; see the General Discussion). This experiment also showed that 24-day-olds trained with longer ISIs responded with higher frequency in unpaired conditions than in standard delay conditioning procedures, but these responses were small and inconsistently timed.

\section{GENERAL DISCUSSION}

These two experiments show that acquisition of conditioned eyeblink responses in postweanling (24-day-old) rat pups is modulated by US intensity and ISI in a manner that is generally similar to that found in adult subjects. Acquisition of CRs proceeded faster and reached higher levels at $3 \mathrm{~mA}$ than at $1 \mathrm{~mA}$ (Experiment 1), with acquisition at $2 \mathrm{~mA}$ (Experiment 2) being intermediate. The optimal ISI for 24-day-olds appeared to be no longer than $280 \mathrm{msec}$. In striking contrast, acquisition of conditioned eyeblink responses in preweanling (17-day-old) rat 
ISI 280
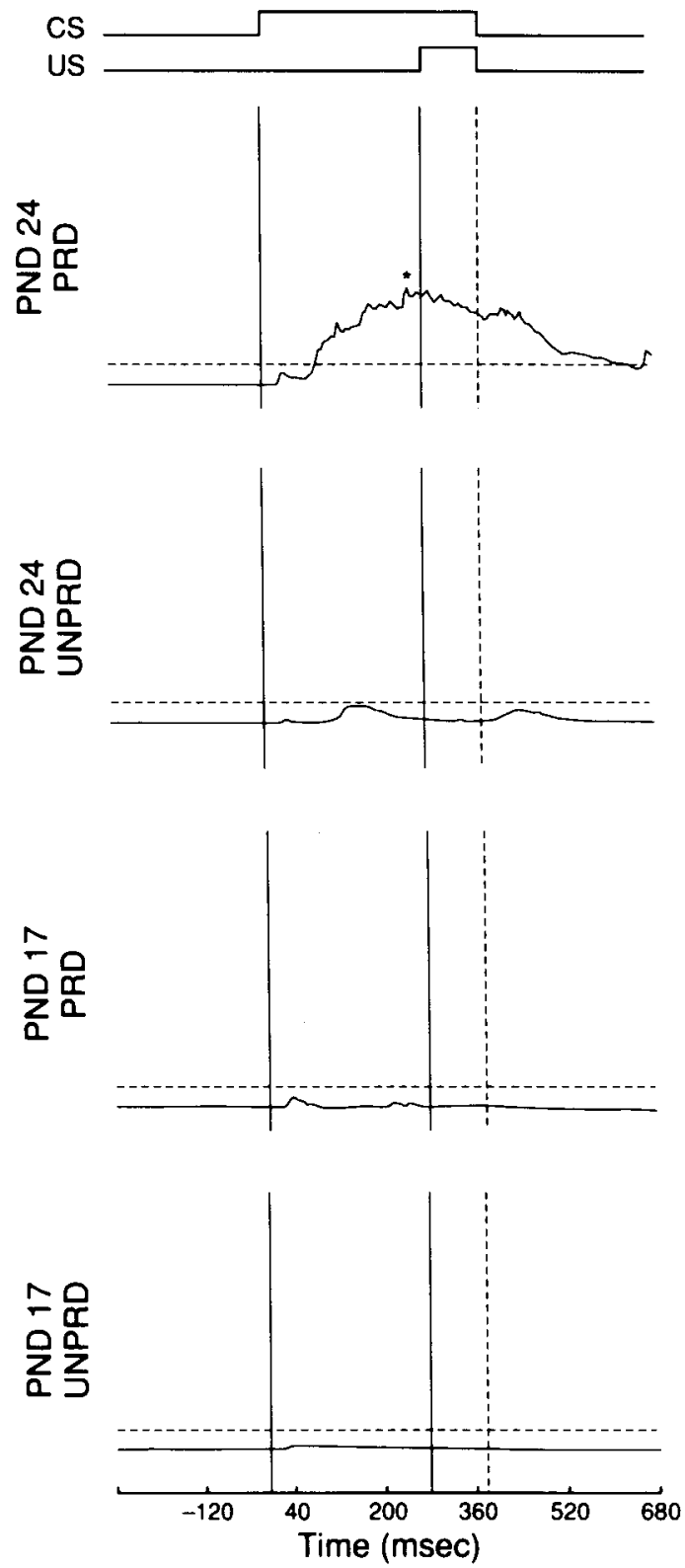

ISI 1960
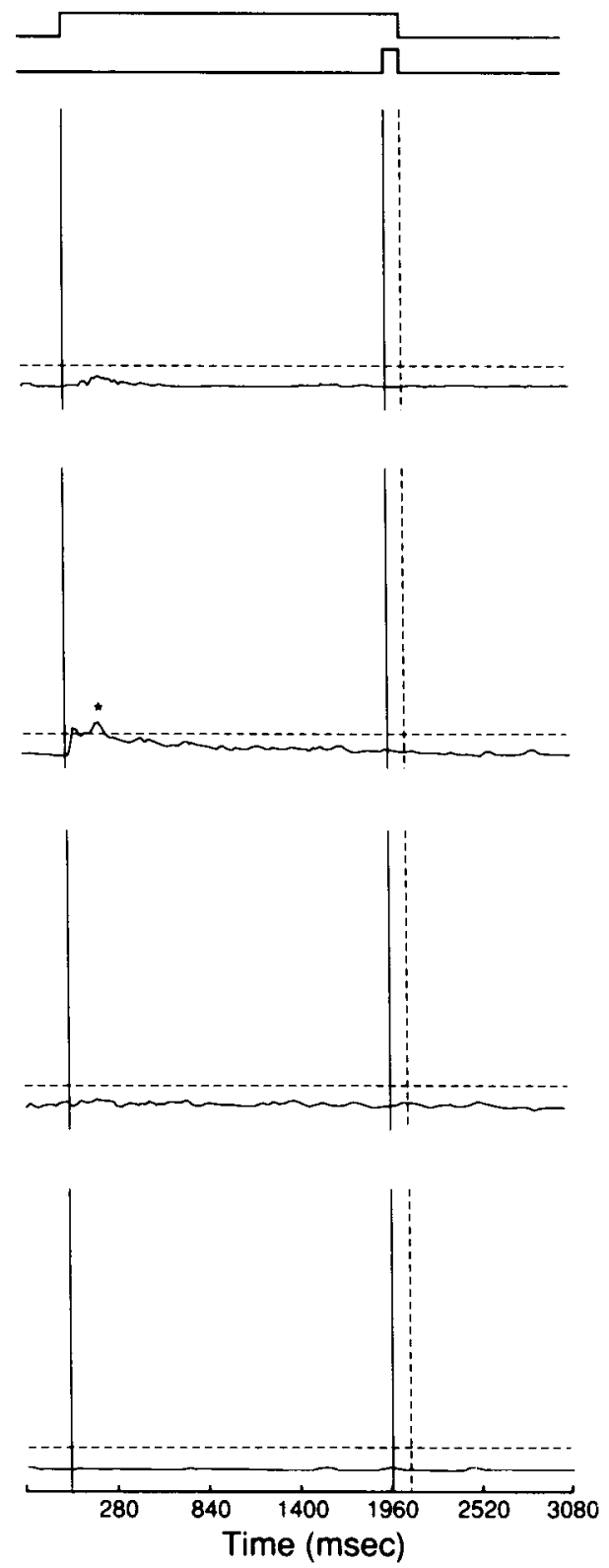

Figure 5. Representative averaged responses from the third training session of 17- and 24-day-old pups on conditioned stimulus (CS) alone trials, trained in both paired and unpaired conditions, at either a 280- (left) or a 1,960-(right) msec interstimulus interval (ISI). CS and unconditioned stimulus (US) onset and duration are indicated at top. Solid vertical lines indicate CS and US onsets, dotted vertical line indicates CS and US offsets; dotted horizontal line indicates response threshold. Note change in time scale for each ISI. (PND = postnatal day.)

pups was never obtained, even with a very intense 3-mA US or at a number of long ISIs. These results indicate that the difference between 17- and 24-day-olds observed previously (Stanton et al., 1992) was not due simply to the use of too low a US intensity or too short an ISI, but rather reflected a more fundamental difference in the ability to acquire conditioned eyeblink responses.
The inability to condition preweanling pups by variations in US intensity or ISI does not preclude the possibility that other parametric manipulations would support robust conditioning. Several manipulations could be examined toward this end, such as increasing the number of conditioning trials, spacing trials over shorter sessions, varying the intertrial interval, varying the $C S$ modality 
(e.g., a vibrotactile CS), varying the tone frequency and intensity, varying the training context (e.g., the presence of nest cues), and altering rearing conditions (e.g., early handling). We are currently examining some of these possibilities to better explore conditions that may alter the developmental trend revealed with this rat eyeblink conditioning preparation.

While further parametric manipulations may provide a better assessment of the learning abilities of infant rats in eyeblink conditioning, the results of this study suggest that it may be at least equally useful to focus attention on neurobiological explanations for the developmental increase in conditioning rate (Stanton et al., 1992). The development of eyeblink conditioning may reflect the maturation of brain systems that modulate the rate of conditioning. As we have indicated previously (Stanton et al., 1992), both the septohippocampal cholinergic system and the cerebellar cortex show substantial postnatal development in the rat (Altman, 1982; Altman \& Bayer, 1975; Ben-Barak \& Dudai, 1980) and can modulate the rate of eyeblink conditioning in adult rabbits (Berry, Weisz, \& Mamounas, 1987; Lavond \& Steinmetz, 1989). Indeed, preliminary studies in our laboratory indicate that manipulations of cerebellar development impair acquisition of eyeblink conditioning in weanling rats (Freeman \& Stanton, 1992; Stanton \& Freeman, 1992). It may be that the developmental trend in eyeblink conditioning depends on the maturation of neuroanatomical systems that modulate acquisition rate in adult animals.

The findings in this study and in an earlier report (Stanton et al., 1992) have demonstrated that eyeblink conditioning can be used for examining the ontogeny of associative learning and that the properties of eyeblink conditioning generalize across species. The increased rate of conditioning in 24-day-old rats as a function of US intensity shows a pattern similar to the findings in adult humans and rabbits (Smith, 1968; Spence \& Platt, 1966). The decrement in conditioning with long ISIs observed in 24-day-old rats is also similar in pattern to the findings of studies of ISI functions in adult rabbits. However, conditioning declined more sharply with increases in ISI in 24-day-old rats than in adult rabbits (Schneiderman \& Gormezano, 1964; Smith, 1968). Whether this decline reflects fundamental differences of a comparative or developmental nature or merely differences in procedural variables across studies remains to be determined. In any case, the properties of eyeblink conditioning in the weanling rat appear to be generally similar to those observed in other species.

The finding that conditioning in 17-day-old rats does not improve with longer ISIs appears to differ from the findings of eyeblink conditioning in human infants (Litthe et al., 1984). However, methodological differences and perhaps differences in the maturational state of the two infant species may explain the effects of ISI variation in the two studies. It is also possible that the neuroanatomical systems mediating learning with longer ISIs are less mature in the 17-day-old rat than in the neonatal human. Alternatively, it is possible that 17 days of age is past the period in rodent ontogeny when longer ISIs facilitate conditioning. This effect in leg flexion conditioning occurs in the newborn rat (Bachevalier \& Blozovski, 1980).

However, regardless of which factor accounts for the difference in the effects of conditioning with longer ISIs, the findings from eyeblink conditioning studies in infant humans and rats indicate that this form of conditioning develops postnatally. Indeed, even with a $1,500-\mathrm{msec}$ ISI, human infants produce only $20 \%-30 \%$ CRs. It is clear, then, that the eyeblink conditioning preparation can be extended to the study of the ontogeny of learning and that there is general agreement among studies that have used the EBC preparation in rats, rabbits, and humans.

\section{REFERENCES}

Altman, J. (1982). Morphological development of the rat cerebellum and some of its mechanisms. In S. L. Palay \& V. Chan-Palay (Eds.), The cerebellum: New vistas (pp. 8-49). Berlin: Springer-Verlag.

Altman, J., \& Bayer, S. (1975). Postnatal development of the hippocampal dentate gyrus under normal and experimental conditions. In R. L. Isaacson \& K. H. Pribram (Eds.), The hippocampus: Structure and development (Vol. 1, pp. 95-122). New York: Plenum

Amsel, A., Stanton, M. E. (1980). Ontogeny and phylogeny of paradoxical reward effects. In J. S. Rosenblatt, R. A. Hinde, C. Beer, \& M. Busnel (Eds.), Advances in the study of behavior (Vol. 11, pp. 227-274). New York: Academic Press.

Bacheval.ier, J., \& Blozovski, D. (1980). Acquisition and retention of classical conditioning in the newborn rat. Developmental Psychology, 13, 519-526.

Ben-Barak, J., Dudai, Y. (1980). Early septal lesion: Effect on the development of the cholinergic system in rat hippocampus. Brain Research, 185, 323-334.

BerRy, S. D., Weisz, D. J., \& Mamounas, L. A. (1987). Neural correlates of acquisition rate. In I. Gormezano, W. F. Prokasy, \& R. F. Thompson (Eds.), Classical conditioning (3rd ed., pp. 255-274). Hillsdale, NJ: Eribaum.

Freeman, J. H., JR., Stanton, M. E. (1992). Early cerebellectomy impairs eyeblink conditioning in the infant rat. Sociery for Neuroscience Abstracts, 18, 1559.

Gilbert, M. E., \& CAIN, D. P. (1980). Electrode implantation in infant rats for kindling and chronic brain recording. Behavioral Brain Research, 1, 553-555.

Kimble, G. A. (1947). Conditioning as a function of the time between conditioned and unconditioned stimuli. Journal of Experimental Psychology, 37, 1-15.

Lavond, D. G., Steinmetz, J. E. (1989). Acquisition of classical conditioning after removal of cerebellar cortex. Behavioural Brain Research, 33, 113-164.

Little, A. H., Lipsitt, L. P., Rovee-Collier, C. (1984). Classical conditioning and retention of the infant's eyelid response: Effects of age and interstimulus interval. Journal of Experimental Child Psy. chology, 37, 512-524.

Powell, D. A., Buchanan, S. L., Hernandez, L. L. (1991). Classical (Pavlovian) conditioning models of age-related changes in as sociative learning and their neurobiological substrates. Progress in Neurobiology, 36, 201-228.

SChneiderman, N., Gormezano, 1. (1964). Conditioning of the nictitating membrane of the rabbit as a function of CS-US interval. Journal of Comparative \& Physiological Psychology, 57, 188-195.

SMITH, M. C. (1968). CS-US interval and US intensity in classical conditioning of the rabbit's nictitating membrane response. Joumal of Comparative \& Physiological Psychology, 66, 679-687. 
Smith, M. C., Coleman, S. R., \& Gormezano, I. (1969). Classical conditioning of the rabbit's nictitating membrane response at backward, simultaneous, and forward CS-US intervals. Journal of Comparative \& Physiological Psychology, 69, 226-231.

SKELton, R. W. (1988). Bilateral cerebellar lesions disrupt conditioned eyelid responses in unrestrained rats. Behavioral Neuroscience, 102 , 586-590.

Spear, N. E., \& Campbell, B. A. (EDs.) (1979). Ontogeny of learning and memory. Hillsdale, $\mathrm{NJ}$ : Erlbaum.

SPEAR, N. E., \& RUDY, J. W. (1991). Tests of the ontogeny of learning and memory: Issues, methods, and results. In H. N. Shair, G. A. Barr, \& M. A. Hofer (Eds.), Developmental psychobiology: New methods and changing concepts (pp. 84-113). New York: Oxford University Press.

SPenCe, K. W., \& Platt, J. R. (1966). UCS intensity and performance in eyelid conditioning. Psychological Bulletin, 65, 1-10.
Stanton, M. E., \& Freeman, J. H., JR. (1992). Distuptions of cerebellar development impair eyeblink conditioning in the infant rat. Society for Neuroscience Abstracts, 18, 1559.

Stanton, M. E., Freeman, J. H., \& Skelton, R. W. (1992). Eyeblink conditioning in the developing rat. Behavioral Neuroscience, 106, 1-9.

Thompson, R. F. (1988a). Classical conditioning: The Rosetta stone for brain substrates of age-related deficits in learning and memory. Neurobiology of Aging, 9, 547-548.

Thompson, R. F. (1988b). The neural basis of basic associative learning of discrete behavioral responses. Trends in Neurosciences, 11, 152-155.

(Manuscript received December 22, 1992; revision accepted for publication April 2, 1993.) 